\title{
Crustal and Upper-Mantle Structure beneath Saudi Arabia from receiver functions and surface wave analysis
}

\author{
P. Martin Mai ${ }^{1}$, Jordi Julià ${ }^{2}$, and Zheng Tang ${ }^{1}$ \\ ${ }^{1}$ King Abdullah University of Science and Technology, Division of Physical Sciences and Engineering, \\ Thuwal, 23955-6900, Saudi Arabia (martin.mai@kaust.edu.sa) \\ ${ }^{2}$ Universidade Federal do Rio Grande do Norte, Brasil
}

\begin{abstract}
Using receiver-functions and surface-wave dispersion curves, we study the crustal and uppermantle structure of Saudi Arabia. Our results reveal first-order differences in crustal thickness between the Arabian Shield in the west and the Arabian Platform in the east. Moho depths generally increase eastwards, while crustal thickness varies strongly in the west over the volcanic regions and near the Red Sea. Localized zones of increased P-wave speeds in the west may indicate solidified magmatic intrusions within the area of recent volcanism. Our receiverfunction analysis for deep converted phases reveals that the transition zone thickness between the $410 \mathrm{~km}$ and the $660 \mathrm{~km}$ discontinuities is not anomalously thinned, refuting the hypothesis of a small localized mantle plume as the origin for the volcanic activity in western Saudi Arabia. Our results suggest that the volcanism in western Arabia may be due to the lithospheric mantle being heated from below by lateral flow from the Afar and (possibly) Jordan plumes. This triggers localized melts that ascend adiabatically through the lithosphere as magma diapirs. Recent xenoliths measurements that provide information on temperatures and depths of melting are overall consistent with this hypothesis. However, further dedicated localized tomographic studies are needed to decipher the details of the origin of the volcanism and its relation to overall geodynamics of the region.
\end{abstract}




\section{Introduction}

The Arabian Plate consists of the western Arabian Shield and the eastern Arabian Platform (Figure 1). While the Arabian Platform is predominantly composed of Paleozoic, Mesozoic and Cenozoic sedimentary rocks with eastwardly increasing thickness (Brown, 1972; Stoeser and Camp, 1985), the Arabian Shield is a complex assemblage of Proterozoic terrains, separated by major ophiolite-bearing suture zones (Schmidt et al., 1979). Several previous studies investigated the large-scale lithospheric structure of Saudi Arabia, but only sparse datasets were available at that time (e.g., Sandvol et al., 1998; Kumar et al., 2002; Julià et al., 2003; Al-Damegh et al., 2005; Tkalčić et al., 2006; Hansen et al., 2007). These studies revealed that Moho depth generally increases eastwards, but also indicated that lateral Moho-depth variations exist in the west. However, due to the complex geology and tectonic history of the Arabian plate, these spatially coarse measurements of crustal thickness and lithospheric structure do not allow more detailed interpretation on the correlations between deep Earth structure and surface geology.

Moreover, the geology and recent tectonic history of western Saudi Arabia is strongly affected by the opening of the Red Sea that started when Arabia began to separate from Africa 230 Ma ago (Camp and Roobol, 1992; Bosworth et al., 2005; Garfunkel and Beyth, 2006). The Red Sea opening is thought to be governed by periods of both passive and active rifting. Rifting initiated passively, and was followed by a period of active rifting (Camp and Roobol, 1992; Ebinger and Sleep, 1998; Daradich et al., 2003). Rifting is also non-uniform along the Red Sea. The southern Red Sea (south of $\sim 21^{\circ} \mathrm{N}$ ) already shows seafloor spreading and volcanic activity (Ebinger and Sleep, 1998; Daradich et al., 2003; Chang et al., 2011; Xu and Jónsson, 2014), while the northern Red Sea (north of $\sim 21^{\circ} \mathrm{N}$ ) is interpreted as an active rift at the end of its continental stage that transitions into oceanic seafloor spreading (Cochran and Martinez, 1988).

Western Saudi Arabia is dotted with prominent Cenozoic volcanic regions (so-called harrats, Figures 1 and 2). The detailed crustal and upper mantle structure underneath these lava fields is still poorly known, although recent studies investigated the velocity structure underneath Harrat Lunayyir (Hansen et al. 2013; Koulakov et al, 2015), where a stalled dike intrusion caused significant seismic activity in 2009 (Pallister et al., 2009). In fact, the exact origin of these lava fields is not well understood. They are found to become progressively younger northwards along the north-south oriented Makkah-Madinah-Nafud (MMN) line (Fig. 1). They also show a 
bimodal chemical character; older lavas (30-20 Ma) are tholeiitic to transitional in composition, and younger volcanics (12 Ma to recent) are transitional to strong-alkali. The genesis of the older harrats, approximately oriented parallel to the Red Sea, is commonly associated with the early rifting stage of the Red Sea. However, it remains elusive how the harrats and their recent magmatic activities are related to the current rift-axis of the Red Sea, which is located 200-400 $\mathrm{km}$ farther to the west. A local mantle plume beneath the Arabian shield was suggested by Camp and Roobol (1992), while Chang and van der Lee (2011) proposed that the Cenozoic volcanism may be due to either lateral mantle flow from the Afar and, perhaps, the Jordan hotspot. A region of deep $(\sim 150 \mathrm{~km})$ low shear velocities is mapped under the southern Red Sea and the western Arabian plate that may be considered as an indication for lateral mantle flow from the Afar (Chang et al., 2011). The global isotropic and radially anistropic mantle-structure model SGLOBE-rani (Chang et al., 2015) finds a broad lower mantle low-velocity region beneath southern Africa ("Africa superplume") that connects to the upper-mantle low-velocity zone beneath the Afar, but the relation of to the low-velocity region underneath western Arabia to this large-scale low-velocity zone remains unclear. Recent regional tomography studies confirm the ambiguous spatial relation between the location of the Cenozoic volcanism in western Saudi Arabia, the rift axis of the Red Sea (and an expected zone of low shear-wave speed underneath it), and a more deeply rooted low-shear-wave speed region of unknown origin (e.g. Chang et al., 2011). This shear-wave speed anomaly is estimated to be $\sim 500 \mathrm{~km}$ wide at a depth of $\sim 100-300$ $\mathrm{km}$, and trends northwards, approximately parallel to the MMN-line .

To understand the geodynamics and present-day geology specifically of western Saudi Arabia, the origin and activity of the harrat volcanism needs to be investigated. Is the volcanism controlled by a localized small plume underneath western Saudi Arabia, or by lateral flow of mantle material from Afar? What does the deeper lithospheric structure look like? Is there any indication in the thickness of the upper mantle transition zone that may hint at the presence of a deep heat source, potentially related to a localized mantle plume? Can we reconcile the volcanism and related seismological observations/parameters with previous petrological work on xenoliths from various harrats that provide point-wise estimates of crustal temperature-pressure conditions (e.g., McGuire, 1988)?

Here, we combine two sets of receiver-function studies that help to illuminate the crustal structure and the upper-mantle transition zone, and then relate our findings to information 
gleaned from xenolith data on pressure- and temperature-dependent melting. First, we summarize our recent work focused on jointly inverting teleseismic P-receiver functions and Rayleigh wave dispersion curves at 56 broadband stations across Saudi Arabia. The joint inversion reduces the non-uniqueness of the receiver-function inversion and its starting-model dependence. We then describe our observed lateral variations in crustal thickness and shear-wave speeds in the crust and uppermost mantle. These measurements allow us to estimate the temperature of the mantle lid, which displays significant lateral variations that we reconcile with thermobarometric data from xenolith analyses. The picture emerging from this line of work supports localized small-scale melt ascent from the mantle into the crust. Second, we analyze a dataset of over 4,500 teleseismic P-waveforms recorded at $\sim 100$ broadband stations in the region. This allows us to test the hypothesis of a deep mantle plume under Arabia and/or Jordan, based on estimates of the thickness of the upper-mantle transition zone, which is defined by temperature-dependent phase transformations in the olivine mineral system (nominally at 410 and $660 \mathrm{~km} \mathrm{depth).} \mathrm{Variations} \mathrm{in} \mathrm{transition-zone} \mathrm{thickness} \mathrm{may} \mathrm{serve} \mathrm{as} \mathrm{a} \mathrm{proxy} \mathrm{for} \mathrm{transition-}$ zone temperature, such that a positive temperature anomaly due to hot mantle upwellings leads to a thin transition zone. This part of our analysis demonstrates that the transition zone is thermally unperturbed under the Arabian shield.

Finally, we discuss our combined findings, related to Moho depth and its lateral variations, inferred mantle-lid temperatures, previous xenoliths studies in the region, and our results on transition-zone thickness. These results refute the presence of a mantle plume below western Arabia. However, our analyses are consistent with lateral flow from the Afar and/or Jordan plume as a plausible source for the young harrat volcanism in the region. The precise origin of the individual harrats cannot be determined with the available data, calling for dedicated high resolution experiments (small-scale seismic networks and local tomographic studies). However, the presence of localized zones with high $\mathrm{Vp} / \mathrm{Vs}$-ratios, indicative of partial melts, as well as localized high P-wave anomalies, potentially due to solidified melts, suggest episodic melt ascent into the crust. 


\section{Data and Data Processing}

Since 2006, the Saudi Geological Survey (SGS) has operated the permanent Saudi National Seismic Network (SNSN), which consists of modern broadband seismic sensors. The number of stations was increased over time to over 200 (as of December 2016). Stations are installed at an average spacing of $\sim 70 \mathrm{~km}$ in western Saudi Arabia, but at much larger and irregular spacing in the Eastern Province (Figure 2). Locally, the network is densified in areas of special interest, such as regions of increased seismicity due to ongoing deep-seated volcanic processes. The SNSN stations are equipped with either T40 or T120 Nanometrics sensors, whose instrument response is flat up to $40 \mathrm{~s}$ and $120 \mathrm{~s}$, respectively. At several SNSN-sites STS-2 Streckeisen instruments are operated. The recorded data are sent via VSAT to the National Center for Earthquakes and Volcanoes (NCEV), where routine earthquake detection and location is conducted, and the data is archived. We utilize the seismic dataset described subsequently to estimate the crustal and upper-mantle shear-wave speed (i.e., S-wave velocity structure) underneath Saudi Arabia.

Applying rigorous data-quality criteria, we select a subset of 56 SNSN stations installed until late 2012 (Figure 2). Since the modern SGS broadband seismic array began operating only in 2006, our database is limited to 157 earthquakes at teleseismic distances (epicentral distances $\Delta=\left[30^{\circ} ; 90^{\circ}\right]$, no depth constraints) with $\mathrm{m}_{\mathrm{b}}>5.5$. Most events arrive from back-azimuths between $25^{\circ}$ and $110^{\circ}$, and epicentral distances between $60^{\circ}$ and $90^{\circ}$ (hence, their ray-parameters fall between 0.04 and $0.06 \mathrm{~s} / \mathrm{km}$ ), corresponding to predominant source locations in the subduction zones of the western Pacific and Eurasian plates. For this dataset, we calculate receiver functions $(\mathrm{RF})$ from the teleseismic P-waveforms, while station-specific surface-wave dispersion (SWD) curves were extracted from the independent tomographic study of Pasyanos (2005). We then jointly invert the RFs and SWD curves to estimate the depth-dependent S-wave speed underneath each station (Tang et al., 2016).

RFs are time series calculated by deconvolving the vertical component of motion from the corresponding horizontal components (Figure 3). The deconvolution removes the signature of the instrument response and the source time functions, leaving the near-receiver propagation effects in the deconvolved waveforms (Langston, 1979). For a simple layer over half-space model, the RF time series contains the direct P-wave, the P-to-S conversion (Ps) at the major 
internal discontinuity, and two reverberations ( $\mathrm{PpPs}$ and PsPs $+\mathrm{PpSs}$ ) between the free surface and the discontinuity (Figure 3a). The largest amplitudes in the RF waveforms are generally associated with the crust-mantle boundary (i.e., the Mohorovicic discontinuity, "Moho"). Therefore, modeling the S-P traveltimes associated with those amplitudes can be used to constrain crustal thickness and the bulk Vp/Vs ratio of the crust (e.g., Zhu and Kanamori, 2000). More complex structures involving multiple seismic discontinuities complicate the RF waveforms by adding further Ps conversions and reverberations due to the interaction of the incoming P-wavefront with each discontinuity. Detailed modeling of RF waveforms therefore allows estimating depth-dependent variations in the S-velocity below the recording station (e.g., Owens et al., 1984; Julià et al., 1998).

We compute both radial and transverse RFs by applying an iterative time-domain deconvolution method (Ligorría and Ammon, 1999), with 500 iterations. Before deconvolution, we cut the waveforms $10 \mathrm{~s}$ before and $110 \mathrm{~s}$ after the teleseismic P-wave arrival, remove the mean, de-trend, taper with a 5\% cosine window, and band-pass filter the seismograms between 0.05 and $4 \mathrm{~Hz}$ to remove low- and high-frequency noise. Seismograms are then down-sampled to 10 samples per second before rotating the horizontal components into the great-circle path to obtain the radial and tangential component seismograms. Furthermore, we compute the RFs at two overlapping frequency ranges with $\mathrm{fc}<0.25 \mathrm{~Hz}$ and $\mathrm{fc}<1.25 \mathrm{~Hz}$, using an acausal Gaussian filter with width factors of $\mathrm{a}=2.5$ and $\mathrm{a}=1.0$, which helps discriminating rapid velocity variations from gradual velocity transitions (Julià, 2007). An automatic quality control is applied to the deconvolved waveforms to remove RFs that do not reproduce at least $85 \%$ of the original horizontal waveforms when convolved back with the corresponding vertical traces. Finally, both radial and transverse RFs are visually inspected, and unstable and/or significantly distorted RFs are removed from the dataset. Figure 4 displays selected RFs averages for several stations (computed with a Gaussian width of 2.5). For most stations, the radial RFs display clear Ps conversions and multiples due to the Moho discontinuity. Also, the transverse RFs reveal comparatively small amplitudes, inferring a nearly isotropic and laterally homogenous underlying medium. The results of the RF-analysis for crustal thickness and upper-mantle lid properties are described in detail in Section 3.

RFs are also utilized to map variations in transition zone thickness under the Arabian Peninsula. The selection criteria for the seismic sources are the same as for the crustal study: 
magnitude $\mathrm{m}_{\mathrm{b}} 5.5$ or larger, epicentral distances between $30^{\circ}$ and $90^{\circ}$, and no restrictions on source depth. To extend our sampling further north, we include additional seismic stations in Israel and Jordan, considering broadband stations from the Israeli Broadband Seismic Network (GII-Net) and from the DEad SEa Rift Transect (DESERT) temporary deployment (see e.g. Mohsen et al., 2005) for which data are publically accessible. GII-Net stations are equipped with Streckeisen STS-2 sensors and Quanterra Q380 dataloggers, and they continuously sample at 20, 40 or $80 \mathrm{~Hz}$, depending on the station. The DESERT stations include a variety of sensors - either Streckeisen STS-2, Guralp CMG-3T, and Guralp CMG-40T - connected to RefTek 72A digitizers; these stations sample at either 20 or $50 \mathrm{~Hz}$. Except for the CMT-40T, all sensors have a flat response in velocity down to $120 \mathrm{~s}$. Overall, more than 20,000 teleseismic P-waveforms recorded at 120 broadband stations across the study area were selected for transition zone thickness analysis.

Processing the teleseismic P-waveforms to obtain RFs for transition zone analysis closely follows that applied to the waveforms for the crustal study, with the only difference being the width of the chosen Gaussian filter. The original P-waveforms are windowed $10 \mathrm{~s}$ before and 120 $\mathrm{s}$ after the P-wave arrival, demeaned, detrended, and tapered with a 5\% cosine taper before applying a high-pass filter at $20 \mathrm{~s}$ to eliminate long-period noise. The data are also decimated to 10 samples per second, and are then rotated into the great-circle path and low-pass filtered with a Gaussian filter of width of $0.5\left(f_{c}<0.2 \mathrm{~Hz}\right)$ before deconvolution. We then apply a time-domain deconvolution of the vertical component from the corresponding radial and transverse components of the teleseismic P-waveforms using the iterative procedure of Ligorría and Ammon (1999), again with 500 iterations. The resulting time series are then convolved with a Gaussian pulse with a width of 0.5 . As with the crustal RFs, we conduct quality control by convolving the vertical component with the radial RF to assess the percentage of recovery of the original radial component, and those records with a recovery under $85 \%$ are automatically rejected. The transverse RFs are then visually inspected, and those displaying amplitudes comparable to the radial component are excluded from further analysis. Finally, the remaining radial RFs are superimposed to visually identify and eliminate possible outliers. In total, 7010 RFs pass our quality control and are utilized in the mapping of the transition zone thickness. An additional step in the quality control is performing single-station stacks with the selected receiver functions to assess the recovery of the P410s and P660s converted phases. The single-station 
stacks are produced after migrating the RFs into the depth domain and then averaging all migrated RFs for a given station. Migration is achieved by mapping S-P travel times in the RFs to P-to-S conversion depths after ray-tracing through the global velocity model ak135 (Kennett et al., 1995); notice that our velocity models do not reach transition zone depths, and hence cannot be utilized for ray-tracing in this case. The mapping is performed at $10 \mathrm{~km}$ depth intervals for depths between 0 and $800 \mathrm{~km}$ using the TauP Toolkit (Crotwell et al., 1999). Our singlestation migrations show an excellent recovery of the P660s conversion and generally good recovery of the P410s conversion. Further details and results focused on using RFs to more accurately map the transition zone thickness are described in Section 4.

\section{Crustal Structure from Receiver Function and Surface-Wave Inversion}

We apply two standard techniques to our RF dataset to extract information about crustal structure under each recording station. First, we use the H-א stacking procedure of Zhu and Kanamori

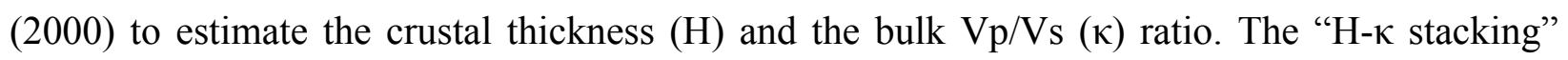
approach constructs a stacking surface by adding RF amplitudes along S-P travel-times curves for a range of crustal models that are assumed to consist of a single layer over a half-space. The amplitudes are thus stacked along phase move-out curves for the Ps, PpPs and PpSs+PsPs phases for each possible pair of $\mathrm{H}$ and $\kappa$ within pre-defined ranges and at regular intervals. If the true model under the given station can be well approximated by a layer-over-half space model, then the stacking surface will display a single best-fitting maximum for the values of $\mathrm{H}$ and $\kappa$ that

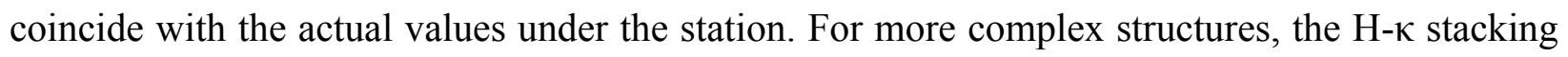
surface may display multiple maxima corresponding to other intra-crustal discontinuities or to artifacts from combining P-to-S conversions from different discontinuities. Thus, this method alone provides only a first-order estimation for $\mathrm{H}$ and $\kappa$ for the crust.

Therefore, we subsequently invert the radial RFs jointly with fundamental-mode Rayleigh-wave group velocities to develop 1D velocity-depth profiles that constrain the detailed S-velocity variation with depth (Figure 5), following the approach described by Julià et al. (2000; 2003). Both RFs and SWDs are mainly sensitive to S-wave velocity, but they help to constrain different features of the velocity-depth profiles. RFs constrain the velocity contrast across the 
discontinuities, and the S-P travel times between the discontinuity and the surface, while SWD measurements control absolute S-velocity averages within frequency-dependent depth-ranges. In the ideal case of noise-free observations, jointly inverting RFs and SWDs uniquely allows for detailed estimation of depth-dependent S-velocity variations (Julià et al., 2000; 2003), thus reducing the dependence on the starting model that characterizes the RF-only inversion (Ammon et al., 1990).

Our starting model for the joint inversion is parameterized as a stack of thin layers with variable S-velocity. Layer thicknesses are $2.5 \mathrm{~km}$ at crustal and uppermost mantle levels, and then progressively increase to $5 \mathrm{~km}$ at lithospheric mantle levels, and $10 \mathrm{~km}$ at larger depths. The $\mathrm{P}$-velocity is calculated from the S-velocity by assuming an a priori $\mathrm{Vp} / \mathrm{Vs}$ ratio for each layer, while the density is obtained from the P-velocity using an empirical relationship for crustal rocks (Berteussen, 1977). The starting model consists of a $40 \mathrm{~km}$ thick crust with a gradual increase in S-wave speed from 3.4 to $4.0 \mathrm{~km} / \mathrm{s}$, overlying an uppermost mantle with velocities around 4.5 $\mathrm{km} / \mathrm{s}$ down to $\sim 180 \mathrm{~km}$ depth. The bottom portion of the starting model follows a flattened PREM (Dziewonski and Anderson, 1981), and is parameterized to a depth of $\sim 400 \mathrm{~km}$.

Our results are described in detail in Tang et al. (2016) and are summarized here (Figure 6). We find significant lateral variations in crustal thickness, shear-wave velocity, and bulk $\mathrm{Vp} / \mathrm{Vs}$ ratio. The Arabian shield has a $27.5-45.0 \mathrm{~km}$ thick crust with crustal shear-velocities of $3.48-3.95 \mathrm{~km} / \mathrm{s}$ and an average bulk $\mathrm{Vp} / \mathrm{Vs}$ ratio of $1.73 \pm 0.07$. In the densely instrumented volcanic region of Harrat Lunayyir, the crustal thickness ranges between 35.0 and $37.5 \mathrm{~km}$, while the crustal S-velocity ranges between 3.85 and $3.94 \mathrm{~km} / \mathrm{s}$, with average $\mathrm{Vp} / \mathrm{Vs}$ of $1.79 \pm 0.11$. In the northern Harrat Rahat, the crustal thickness varies between 32.5 and $37.5 \mathrm{~km}$, with crustal Svelocities between 3.76 and $3.88 \mathrm{~km} / \mathrm{s}$ and an average bulk $\mathrm{Vp} / \mathrm{Vs}$ ratio of $1.77 \pm 0.07$. Thinner crust (25.0 - $32.5 \mathrm{~km}$ thick) with strong lateral variations is present along the Saudi Arabian coast of the Red Sea. Beneath the northwestern part of the Arabian platform, we find roughly $35 \mathrm{~km}$ thick crust, with crustal thickness increasing to $40.0-45.0 \mathrm{~km}$ under the eastern platform. The Arabian platform has crustal Vs of $3.44-3.68 \mathrm{~km} / \mathrm{s}$ and average Vp/Vs ratio of $1.77 \pm 0.09$. These results reveal a rapid transition from oceanic to continental crust in the Red Sea margin and the western Arabian shield, as well as remarkable crustal thickening from the Arabian shield to the platform. In addition, we observe that crustal thickness tends to increase from the northern to the southern Arabian shield, parallel to the Red Sea (Figure 6). 
To further investigate the spatial pattern of depth-dependent S-wave speeds and relate it to independent geophysical/geologic data, we estimate the upper mantle lid temperature beneath each station utilizing the first-order Taylor expansion of the pressure-temperature dependence of the shear-wave speed. We assume that the dominant rock type for the upper mantle lid is peridotite, with laboratory measurements for the reference velocity (i.e., S-velocity at pressure 0 kbar and temperature $0^{\circ} \mathrm{C}$ ) and partial derivatives (i.e., pressure and temperature derivatives) taken from Kern and Richter (1981). Pressure is estimated as the crustal overburden, taking into account the densities and layer thicknesses from the inverted models of S-wave speed, while the S-velocity of the lid is estimated as a 3-layer average within the mantle lid portion of our velocity-depth profiles.-The resulting mantle lid temperature and its corresponding uncertainty under each station are displayed in Figure 7; the uncertainties are estimated by error-propagation of the inferred S-wave speed, and are generally in the range $200-300^{\circ} \mathrm{C}$

The most important geophysical signatures we find are the patterns of lateral shear velocity and temperature variation in the upper-mantle lid beneath the Arabian shield (Figure 7) as well as the anomalously high bulk Vp/Vs ratios in the Cenozoic volcanic area of Harrat Lunayyir (Tang et al. 2016). The patterns indicate that the southern (and northern) portion of the shield is characterized by lower shear velocities and higher temperatures across the upper-mantle lid. We interpret these spatial patterns in terms of lateral heating by thermal conduction from a mantle upwelling below Afar (and, perhaps, Jordan) towards the central shield. The presence of high $\mathrm{Vp} / \mathrm{Vs}$ ratios and relatively large, lower crustal S-velocities suggests a compositional anomaly (i.e., solidified magma intrusions from old magmatic episodes), rather than the presence of partial melt under Harrat Lunayyir. Our inferred lower-crustal relatively higher Vs at Harrat Lunayyir is difficult to reconcile with partial melts, but is consistent with a middle-crustal high Vp anomaly observed Hansen et al., (2013). Thus, the magma sources feeding the recent volcanic eruptions are preferentially located in the lithospheric mantle, which is consistent with the model of lateral flow from the Afar and (possibly) Jordan plumes. We speculate the lateral flow heats the bottom of the shield's lithosphere, triggering localized melts in the lower lithosphere that buoyantly rise to the surface on a local scale (perhaps, through zones of crustal weakness). Because we did not find high temperatures in the uppermost mantle lid under those lava fields, we argue that the volcanism in western Arabia may result from small-scale adiabatic ascent of magma diapirs. 


\section{Transition Zone Thickness from Deep Converted Waves}

In this section, we analyze RF measurements to map the thickness of the transition zone between the $410 \mathrm{~km}$ and the $660 \mathrm{~km}$ discontinuity in the Earth's mantle. Figure 8 conceptually displays the pressure-temperature-compositional conditions for these discontinuities and how the exact depths change for either colder or hotter than average regimes. The pressure-temperature dependence $d P / d T$ can be written as:

$$
\frac{d P}{d T}=\frac{L}{T\left(\rho_{2}-\rho_{21}\right)}
$$

where $P$ is pressure, $T$ is temperature, $\rho_{2}-\rho_{1}$ represents density change, and $L$ is the latent heat associated to the phase transformation. For $L>0$, an exothermic process occurs (e.g., at the 410 $\mathrm{km}$ discontinuity); for $L<0$, the process is endothermic (at the $660 \mathrm{~km}$ discontinuity). Because elevated or depressed discontinues lead to changes in the arrival times of the corresponding converted seismic phases, the RF properties will also change. This is illustrated by sample single-station migrated RFs in Figure 9, showing excellent recovery of the P660s conversion and a generally good recovery of the P410s conversion. Some stations display a disrupted P410s conversion (e.g. station \#2, on the eastern platform), while others seem to have a very depressed and thin transition zone (e.g. station \#3, in Jordan).

To map lateral variations in transition-zone thickness under the Arabian Peninsula, we migrate and stack low-frequency (Gaussian width 0.5) P-wave RFs following the variable bin radius stacking scheme (Owens et al., 2000). First, the locations of piercing points (i.e., geographical locations of Ps conversions at a given depth) are determined for all RFs, considering conversion depths between 0 and $800 \mathrm{~km}$ with $10 \mathrm{~km}$ depth intervals and ray-tracing through the global Earth model ak135 (Kennett et al., 1995). Second, a grid of nodes (spaced at $0.50^{\circ}$ ) is defined over the study area sampled by the piercing points. The piercing points are then grouped within bins with radii varying between $0.25^{\circ}$ and $2.00^{\circ}$ around the nodes, with bin radii being set to the smallest value that contained a minimum of 30 piercing points from at least four different stations. In practice, the minimum radius is found by initially setting its value to $0.25^{\circ}$ and progressively increasing it with $0.25^{\circ}$ intervals until the two criteria were met. The location of the piercing points at $410 \mathrm{~km}$ and $660 \mathrm{~km}$ depth are displayed in Figure 10a, estimated 
transition-zone thicknesses are shown in Figure 10b, and the map of bin radii is displayed in Figure 11. After the bins are defined for each node and at each depth, the amplitudes associated to the piercing points within each bin are averaged (stacked) to develop a bin-averaged RF function for each node.

We estimate transition zone thickness by applying an automated "picker" through each of the bin-averaged RFs to determine the migrated depths for the P410s and P660s phase conversions. The automated procedure searches for the largest peak within prescribed depth ranges of $350-500 \mathrm{~km}$ for the P410s and $600-750 \mathrm{~km}$ for the P660s, and calculates transition zone thickness through the difference of the inferred depth values. The results are displayed in Figure $10 \mathrm{~b}$ for nodes with bin radii smaller than or equal to $1.0^{\circ}$. The figure demonstrates that transition zone thickness under the Arabian Shield is close to the nominal value of $250 \mathrm{~km}$ shown in global Earth models, suggesting that the transition zone is not thermally perturbed under the central parts of the Arabian Shield. This rules out the presence of a mantle plume, as proposed by Camp and Roobol (1992). This is further illustrated in Figure 12, where a NW-SE RFs cross-section oriented parallel to the Red Sea coast is displayed. The cross-section shows that the 410 and $660 \mathrm{~km}$ discontinuities are generally well imaged by the RFs, although statically shifted to larger depths. The shift is due to the assumption of a global Earth model with an upper mantle faster than imaged in tomographic studies for the region (e.g. Chang et al., 2011). Realize that the static shift mostly prevents us from recovering absolute depths for the discontinuities bounding the transition zone, having a minimal effect on transition zone thickness (Owens et al., 2000). The cross-section also shows that the 410 and $660 \mathrm{~km}$ discontinuities are disrupted at 300$400 \mathrm{~km}$ from the NW end, which we attribute to a "leaking" effect, deriving from complex wave propagation in the vicinity of the Dead Sea Transform. The cross-section also shows that the 410 is not imaged at distances 1650-1800 km away from the NW end, further emphasizing the need for 3D travel-time corrections to fully interpret the topography of the transition zone discontinuities.

Based on our spatially expanded dataset for transition-zone thickness estimation (Figure 10b), we also observe that under northern Jordan, immediately east of the Dead Sea Transform, the transition zone is anomalously thin (Figure 10b). Such thinning is further demonstrated in Figure 9 through the single-station stack for station \#3, suggesting that the thinning could be on the order of $\sim 50 \mathrm{~km}$ or, equivalently, that the associated thermal anomaly could be $\sim 300 \mathrm{~K}$. 
Interestingly, this anomalous region broadly coincides with the location of the postulated Jordan plume (Chang and Van der Lee, 2011).

\section{Discussion and Conclusions}

The picture emerging from our results outlined in Section 3 is that the Arabian lithospheric mantle is heated from below by lateral flow from the Afar and (possibly) Jordan plumes. This triggers localized melts that ascend adiabatically through the lithosphere as magma diapirs. This interpretation, as discussed in detail by Tang et al. (2016), is based on our observations of mantle lid temperatures increasing towards the location of the Afar plume and the lack of correlation between high lid temperatures and the surface location of the Cenozoic harrats (Figure 7). The possibility of direct heating by a mantle plume under the central shield, as proposed by Camp and Roobol (1992), is ruled out by the lack of transition zone thinning under the shield (Figure 10a) and seismic images of the Arabian upper mantle (e.g., Chang and van der Lee, 2011).

The precise relationship between heating at the base of the lithosphere and surface volcanism is still unknown. Is laterally-transported plume material from Afar melted and entrained under the Arabian Shield to finally make its way up to the surface? Or is this transported plume material just providing the heat to trigger melting that will eventually ascend through the lithosphere? To address these questions, mantle xenolith data may provide relevant information. Xenoliths are inclusions of rock fragments that become entrained in igneous rocks during magmatic eruptions (or emplacement), and they provide temperature, pressure, and compositional information about the Earth's mantle. Konrad et al. (2016) compiled Helium isotope ratios from lava flows and mantle xenoliths from several harrats in Saudi Arabia and Yemen, and demonstrated a bimodal distribution: for Harrat Rahat, along the MMN line,

${ }^{3} \mathrm{He} /{ }^{4} \mathrm{He}$ ratios are in the 9.3-11.8 $\mathrm{Ra}$ range (where $\mathrm{Ra}$ is the atmospheric ratio), suggesting a "weak but detectable plume helium signal"; for all other harrats in the Arabian Shield, ratios are in the 6.8-8.2 Ra range, where the lower bound is representative of the ambient Proterozoic lithospheric mantle, and the upper bound is representative of mixing with the underlying asthenosphere. Konrad et al. (2016) propose that the lithosphere under the MMN line may have been thinned by lateral flow from the Afar plume and, as thermal erosion progressed, convective 
instabilities may have mixed asthenospheric material with overlying lithospheric rocks. Plume material would have then become entrained in the mix for lavas found at Harrat Rahat (directly above the MMN line), but not for the low ${ }^{3} \mathrm{He} /{ }^{4} \mathrm{He}$ harrat basalts found elsewhere. These findings are, to first order, consistent with our interpretation of the Afar and Jordan upwellings being diverted laterally and flooding the base of the Arabian lithosphere. Why entrainment of plume material may only happen beneath Harrat Rahat remains, nonetheless, an open question that requires detailed mapping of the lithosphere-asthenosphere boundary and modeling of lateral asthenospheric flow under the Arabian Shield (e.g., Faccenna et al. 2013).

The bimodal character of Cenozoic volcanics in the Arabian Shield was already reported by Camp and Roobol (1992), who divided its continental magmatism into two distinct phases: an older phase (30 to $20 \mathrm{Ma}$ ) that produced tholeiitic-to-transitional lavas emplaced along NW trends, and a younger phase (12 Ma to Recent) that produced transitional-to-strongly-alkalic lavas emplaced along NS trends. The older phase was related to passive rifting along the Red Sea basin, while the younger one was related to active upwelling from a mantle plume. The bimodal character was further emphasized by petrochemical evidence showing that the younger harrats were derived by greater degrees of partial melting at shallower depths than those harrats of older age. The ${ }^{3} \mathrm{He} /{ }^{4} \mathrm{He}$ ratios reported in Konrad et al. (2016) further emphasize this bimodal character and provide additional evidence for entrainment of plume material or lack thereof in the two phases of magmatism, respectively.

The adiabatic ascent of magma diapirs on a local scale as the feeding mechanism for harrat volcanism, as proposed by the interpretation of our seismic results, is also supported by mantle xenoliths. Kaliwoda et al. (2007) investigated chemical zonation patterns in xenoliths found in Harrat Uwayrid lavas, in the northeastern tip of the Arabian Shield, and identified a first high-T stage (also recorded in other volcanic fields) related to basal flooding of the lithosphere by the Afar plume material, and a renewed heating event of a more local nature, probably caused by ascending and stagnating magmas. The regional high- $\mathrm{T}$ stage was first identified from geothermobarometry on Harrat Al-Kishb samples and geothermal modeling by McGuire and Bohannon (1989). The renewed high-T stage is consistent with our interpretation of an "adiabatic" ascent of magma diapirs, as the local nature of the heating event would not produce a thermal anomaly on a scale large enough to be detected seismically. Interestingly, the regional heating event is postulated to have pervaded the Arabian lithosphere and caused widespread 
partial melt. We remark that widespread partial melting at the base of the lithosphere would remove the necessity for lateral flow of the lithosphere-asthenosphere mix proposed by Konrad et al. (2016) away from the MMN line.

Finally, the role of a possible Jordan plume in the generation of the melts that fed the northern harrats needs further study. On one hand, our velocity models do not sample the mantle lid close enough to the postulated location of the Jordan plume to observe a marked lid temperature increase close to the proposed plume. Geothermobarometry on xenoliths found at Harrat Ash Saam in eastern Jordan, as summarized by Shaw et al. (2007), reveal temperatures of 900-1030 ${ }^{\circ} \mathrm{C}$ at $11-18 \mathrm{kbar}(35-60 \mathrm{~km})$. These temperatures are in the upper (hot) limit of the temperature range inferred for the central shield from seismic velocities and are also similar to temperatures inferred under the two northeastern shield stations (Figure 7). Relatively low ${ }^{3} \mathrm{He} /{ }^{4} \mathrm{He}$ ratios determined for lava flows from Harrat Ash Saam in eastern Jordan suggest a shallow lithosphere-asthenosphere source for the melts and, therefore, no entrainment of a putative Jordan plume.

On the other hand, the only evidence for a Jordan plume are found in seismic studies, such as Chang and van der Lee (2011) who show a vertical seismic cross-sections that depicts a low-velocity anomaly under Jordan, and the current work that reports a thinning of the transition zone under eastern Jordan reported (Figure 10b). Lateral flow and entrainment of Jordan plume material under the Arabian lithosphere, however, is yet to be assessed. Therefore, to unravel the exact source of the volcanism on the Arabian plate and to understand its occurrence in the context of the geodynamic processes associated with the Red Sea opening and the Afar plume, dedicated seismic experiments are needed to create higher-resolution images of the lithosphere in the region.

\section{Acknowledgements}

We thank the Saudi Geological Survey (SGS) for sharing their seismic data with us, in particular Hani Zahran and Mahmoud Salam. Laura Parisi helped to create Figure 6. Many thanks to Najeeb Rasul (SGS Jeddah) for organizing the workshop on "The Geological Setting, Oceanography and Enviroment of the Red Sea" in February 2016 in Jeddah, which inspired this Chapter. We are grateful to anonymous reviewers for their constructive criticism and careful 
reviews that helped to improve this study. The research reported in this publication was supported by funding from King Abdullah University of Science and Technology (KAUST), grant number BAS/1/1339-01-01. We also acknowledge support by Universidade Federal do Rio Grande do Norte for hosting Z.T. during two research visits.

\section{References}

Al-Damegh, K., Sandvol, E., \& Barazangi, M. (2005). Crustal structure of the Arabian plate: new constraints from the analysis of teleseismic receiver functions. Earth and Planetary Science Letters, 231(3), 177-196.

Ammon, C. J., Randall, G. E., \& Zandt, G. (1990). On the nonuniqueness of receiver function inversions. Journal of Geophysical Research: Solid Earth (1978-2012), 95(B10), 1530315318.

Berteussen, K. A. (1977). Moho depth determinations based on spectral-ratio analysis of NORSAR long-period P waves. Physics of the Earth and Planetary Interiors, 15(1), 13-27.

Bosworth, W., Huchon, P., \& McClay, K. (2005). The red sea and gulf of Aden basins. Journal of African Earth Sciences, 43(1), 334-378.

Brown, G. F. (1972). Tectonic map of the Arabian Peninsula (No. 72-52). US Geological Survey.

Camp, V. E., \& Roobol, M. J. (1992). Upwelling asthenosphere beneath western Arabia and its regional implications. Journal of Geophysical Research, 97(B11), 15255-15271.

Chang, S. J., Merino, M., Van der Lee, S., Stein, S., \& Stein, C. A. (2011). Mantle flow beneath Arabia offset from the opening Red Sea. Geophysical Research Letters, 38(4).

Chang, S. J., \& Van der Lee, S. (2011). Mantle plumes and associated flow beneath Arabia and East Africa. Earth and Planetary Science Letters, 302(3), 448-454.

Chang, S.-J., A. M. G. Ferreira, J. Ritsema, H. J. van Heijst, and J. H. Woodhouse (2015), Joint inversion for global isotropic and radially anisotropic mantle structure including crustal thickness perturbations, J. Geophys. Res. Solid Earth, 120, 4278-4300, doi:10.1002/2014JB011824.

Cochran, J. R., \& Martinez, F. (1988). Evidence from the northern Red Sea on the transition from continental to oceanic rifting. Tectonophysics, 153(1-4), 25-53.

Crotwell, H. P., Owens, T. J., \& Ritsema, J. (1999). The TauP Toolkit: Flexible seismic traveltime and ray-path utilities. Seismological Research Letters, 70(2), 154-160. 
Daradich, A., Mitrovica, J. X., Pysklywec, R. N., Willett, S. D., \& Forte, A. M. (2003). Mantle flow, dynamic topography, and rift-flank uplift of Arabia. Geology, 31(10), 901-904.

Dziewonski, A. M., \& Anderson, D. L. (1981). Preliminary reference Earth model. Physics of the earth and planetary interiors, 25(4), 297-356.

Ebinger, C. J., \& Sleep, N. H. (1998). Cenozoic magmatism throughout east Africa resulting from impact of a single plume. Nature, 395(6704), 788-791.

Faccenna, C., Th. Becker, L. Jolivet, M. Keskin (2013). Mantle convection in the Middle East: Reconciling Afar upwelling, Arabia indentation and Aegean trench rollback, Earth and Planetary Science Letters, Vol 375, p. 254-269, 10.1016/j.eps1.2013.05.043

Garfunkel, Z., \& Beyth, M. (2006). Constraints on the structural development of Afar imposed by the kinematics of the major surrounding plates. Geological Society, London, Special Publications, 259(1), 23-42.

Hansen, S. E., DeShon, H. R., Moore Driskell, M. M., \& Al Amri, A. (2013). Investigating the $\mathrm{P}$ wave velocity structure beneath Harrat Lunayyir, northwestern Saudi Arabia, using double difference tomography and earthquakes from the 2009 seismic swarm. Journal of Geophysical Research: Solid Earth, 118(9), 4814-4826.

Hansen, S. E., Rodgers, A. J., Schwartz, S. Y., \& Al-Amri, A. M. (2007). Imaging ruptured lithosphere beneath the Red Sea and Arabian Peninsula. Earth and Planetary Science Letters, 259(3), 256-265.

Julià, J. (2007). Constraining velocity and density contrasts across the crust-mantle boundary with receiver function amplitudes. Geophysical Journal International, 171(1), 286-301.

Julià, J., Ammon, C. J., Herrmann, R. B., \& Correig, A. M. (2000). Joint inversion of receiver function and surface wave dispersion observations. Geophysical Journal International, 143(1), 99-112.

Julià, J., Ammon, C. J., \& Herrmann, R. B. (2003). Lithospheric structure of the Arabian Shield from the joint inversion of receiver functions and surface-wave group velocities. Tectonophysics, 371(1), 1-21.

Julià, J., Vila, J., \& Macià, R. (1998). The receiver structure beneath the Ebro basin, Iberian Peninsula. Bulletin of the Seismological Society of America, 88(6), 1538-1547.

Kaliwoda, M., Altherr, R., \& Meyer, H. P. (2007). Composition and thermal evolution of the lithospheric mantle beneath the Harrat Uwayrid, eastern flank of the Red Sea rift (Saudi Arabia). Lithos, 99(1), 105-120. 
Konrad, K., Graham, D. W., Thornber, C. R., Duncan, R. A., Kent, A. J., \& Al-Amri, A. M. (2016). Asthenosphere-lithosphere interactions in Western Saudi Arabia: Inferences from 3 $\mathrm{He} / 4 \mathrm{He}$ in xenoliths and lava flows from Harrat Hutaymah. Lithos, 248, 339-352.

Koulakov, I., S. El Khrepy, N. Al-Arifi, P. Kuznetsov, and E. Kasatkina1, Structural cause of a missed eruption in the Harrat Lunayyir basaltic field (Saudi Arabia) in 2009, Geology, May 2015; v. 43; no. 5; p. 395-398.

Kumar, M. R., Ramesh, D. S., Saul, J., Sarkar, D., \& Kind, R. (2002). Crustal structure and upper mantle stratigraphy of the Arabian shield. Geophysical Research Letters, 29(8), 130-1.

Kennett, B. L. N., Engdahl, E. R., \& Buland, R. (1995). Constraints on seismic velocities in the Earth from traveltimes. Geophysical Journal International, 122(1), 108-124.

Kern, H., \& Richter, A. (1981). Temperature derivatives of compressional and shear-wave velocities in crustal and mantle rocks at 6 kbar confining pressure. Journal of Geophysics Zeitschrift fuer Geophysik, 49(1), 47-56.

Langston, C. A. (1979). Structure under Mount Rainier, Washington, inferred from teleseismic body waves. Journal of Geophysical Research: Solid Earth (1978-2012), 84(B9), 47494762.

Ligorría, J. P., \& Ammon, C. J. (1999). Iterative deconvolution and receiver-function estimation. Bulletin of the seismological Society of America, 89(5), 1395-1400.

McGuire, A. V. (1988). The mantle beneath the Red Sea margin: xenoliths from western Saudi Arabia. Tectonophysics, 150(1), 101-119.

McGuire, A.V. and Bohannon, R.G. (1989). Timing of mantle upwelling: Evidence for a passive origin for the Red Sea rift. Journal of Geophysical Research 94: doi: 10.1029/88JB03905.

Mohsen, A., Hofstetter, R., Bock, G., Kind, R., Weber, M., Wylegalla, K., \& DESERT Group. (2005). A receiver function study across the Dead Sea Transform. Geophysical Journal International, 160(3), 948-960.

Owens, T. J., Nyblade, A. A., Gurrola, H., \& Langston, C. A. (2000). Mantle transition zone structure beneath Tanzania, East Africa. Geophysical Research Letters, 27(6), 827-830.

Owens, T. J., Zandt, G., \& Taylor, S. R. (1984). Seismic evidence for an ancient rift beneath the Cumberland Plateau, Tennessee: A detailed analysis of broadband teleseismic P waveforms. Journal of Geophysical Research: Solid Earth (1978-2012), 89(B9), 7783-7795.

Pallister, J. S., McCausland, W. A., Jónsson, S., Lu, Z., Zahran, H. M., El Hadidy, S., ... \& Moufti, M. R. (2010). Broad accommodation of rift-related extension recorded by dyke intrusion in Saudi Arabia. Nature Geoscience, 3(10), 705-712. 
Pasyanos, M. E. (2005). A variable resolution surface wave dispersion study of Eurasia, North Africa, and surrounding regions. Journal of Geophysical Research: Solid Earth (1978-2012), 110(B12).

Sandvol, E., Seber, D., Calvert, A., \& Barazangi, M. (1998). Grid search modeling of receiver functions: Implications for crustal structure in the Middle East and North Africa. Journal of Geophysical Research: Solid Earth (1978-2012), 103(B11), 26899-26917.

Schmidt, D. L., Hadley, D. G., \& Stoeser, D. B. (1979). Evolution and Mineralization of the Arabian-Nubian Shield.

Shaw, J. E., Baker, J. A., Kent, A. J. R., Ibrahim, K. M., \& Menzies, M. A. (2007). The geochemistry of the Arabian lithospheric mantle-a source for intraplate volcanism?. Journal of Petrology, 48(8), 1495-1512.

Stoeser, D. B., \& Camp, V. E. (1985). Pan-African microplate accretion of the Arabian Shield. Geological Society of America Bulletin, 96(7), 817-826.

Tang, Z., Julià, J., Zahran, H., \& Mai, P. M. (2016). The lithospheric shear-wave velocity structure of Saudi Arabia: Young volcanism in an old shield. Tectonophysics, 680, 8-27.

Tkalčić, H., Pasyanos, M. E., Rodgers, A. J., Gök, R., Walter, W. R., \& Al Amri, A. (2006). A multistep approach for joint modeling of surface wave dispersion and teleseismic receiver functions: Implications for lithospheric structure of the Arabian Peninsula. Journal of Geophysical Research: Solid Earth (1978-2012), 111(B11).

$\mathrm{Xu}, \mathrm{W}$., \& Jónsson, S. (2014). The 2007-8 volcanic eruption on Jebel at Tair island (Red Sea) observed by satellite radar and optical images. Bulletin of Volcanology, 76(2), 1-14.

Zhu, L., \& Kanamori, H. (2000). Moho depth variation in southern California from teleseismic receiver functions. Journal of Geophysical Research: Solid Earth (1978-2012), 105(B2), 2969-2980. 


\section{Figure Captions}

Figure 1: Geological map of the Arabian plate and neighboring tectonic plates. Major plate boundaries are shown by black lines. The bright-colored regions in the Arabian Shield outline six accreted terranes (Miyan, Hijiaz, Jeddah, Asir, Afif and Ar-Rayn terrane). Areas of recent volcanic activity (past 12 million years) are shown in dark-gray (modified after Tang et al., 2016).

Figure 2: Topographic map of the Arabian Plate and surrounding regions, showing the broadband seismic stations operated by the SGS (cyan circles and triangles), and locations of several other seismic deployments. Note the increased station density in the western part of Saudi Arabia, particularly in regions of recent volcanic activity. Stations marked by circles (including DESERT, GEOFON, PASSCAL, HABE, ISN, KACST and 56 of SGS) are utilized for estimating the transition zone thickness. 56 SGS stations (filled cyan circles) are used for joint inversion to investigate the crustal and upper mantle structures of Saudi Arabia (see Tang et al., 2016). For sites with station names, we show receiver-function examples in Figure 4, for the stations numbered 1-6, in Figure 9.

Figure 3b: Graphical summary of teleseismic waveform characteristics and receiver function processing. (top) At large distances from an earthquake, the first arriving P-wave and the secondary S-wave are well separated; the S-wave is followed by large-amplitude surface waves (here: Rayleigh waves). (bottom right) The complex wavetrain of the P-waves contains information about the earthquake source as well as the Earth structure through which the seismic waves travel, recorded on three mutually perpendicular components. (bottom right) The receiverfunction (RF) processing procedure of the two horizontal components returns a radial and transverse RF; the peaks in the radial RF indicate interaction of the P-wave with the layered structure of the Earth.

Figure 3a: (left) Sketch illustrating how P-waves (blue) and S-waves (red) interact with the subsurface before being recorded at a seismic station located at the Earth surface. (right) Receiver function example that documents the multiple seismic-wave interactions with the layer interface. 
Figure 4: Examples of receiver functions for selected stations, whose names are indicated in the upper right corner. In each panel, the average radial (top) and the transverse (bottom) RFs are shown, with a Gaussian width of 2.5. The small numbers indicate the number of earthquakes used to obtain the displayed RF, their average back-azimuth (and its variation, in degrees), as well as the ray parameter (and its variation, in s/km). The gray-shading beneath each average RF (plotted in black) illustrates the confidence bounds. The red, blue and green arrows provide visual guidance (for a few cases) to identify the Ps conversion, first multiple (PpPs) and second multiple (PpSs + PsPs) described in Figure 3.

Figure 5: Illustration of the joint inversion approach, using receiver functions (top row) and surface-wave dispersion curves (center row), to determine the one-dimensional shear-wave velocity structure underneath station AFFS, located on the Arabian Shield. RF and SWD observations are shown in black, the modeled RF and SWD are shown in red. Iteration steps proceed from left to right, showing how the initial model (red) converges to the final solution (black).

Figure 6: Three-dimensional rendering of the inferred S-wave velocity structure underneath Saudi Arabia. Seismic stations used for the inversion are plotted as triangles, the coastlines of the Arabian Peninsula and east Africa are shown by black lines. Horizontal slices are shown at $4 \mathrm{~km}$ depth intervals, the vertical slices are contoured (black-dotted line) at $0.2 \mathrm{~km} / \mathrm{s}$ intervals. (left) View from south-west. (right) View from south-east. Note the lateral variations of S-wave speed associated with variations in Moho depth, and the crustal thickening from the Arabian shield to the platform.

Figure 7: Estimated upper-mantle lid temperatures across the Arabian Shield. The circle size scales with the uncertainty in the temperature estimation. The dark-gray-shaded regions mark volcanic provinces (modified after Tang et al., 2016)

Figure 8: Conceptual diagram for the thickness of the transition zone between the $410 \mathrm{~km}$ and the $660 \mathrm{~km}$ discontinuities in the Earth's mantle. The pressure-temperature (P-T) diagram shows the phase-equilibrium boundaries for pure $\mathrm{Mg}_{2} \mathrm{SiO}_{4}$ (calculated using Fei et al., 1990). Depending on the temperature gradient, the thickness of the transition changes. A thinned transition zone may be indicative of deep, hot material that signifies a potential mantle plume. 
Figure 9: Examples of six RFs to estimate the transition zones thickness between the $410 \mathrm{~km}$ and $660 \mathrm{~km}$ discontinuities across the Arabian Plate. The gray band around each RF-waveform indicates the confidence interval. Station \#3 shows some indication of a decreases transition zone thickness; all other stations reveal little evidence for transition-zone variations. At station \#2, the transition zone cannot be estimated unambiguously due to a disrupted $410 \mathrm{~km}$ discontinuity. See Figure 2 for station locations.

Figure 10: Transition-zone thickness across the Arabian Plate. (left) Stations (red circles) and piercing points (gray dots); the NW-SE-trending line marks the profile shown in Figure 12. The study area was binned into $0.5^{\circ} \times 0.5^{\circ}$ bins to estimate the transition-zone thickness. (right) The Arabian Shield shows largely a normal transition-zone thickness of around $250 \mathrm{~km}$.

Figure 11: Bin radii at depths of $410 \mathrm{~km}$ and $660 \mathrm{~km}$ for bins containing at least 30 piercing points from at least four different stations (see text for details). The bin size has been color-coded as specified in the legend. Note that the smallest radii $\left(0.25^{\circ}\right)$ are achieved in regions with high piercing-point density. Bins with radii over $1^{\circ}$ (or low piercing point density) were not considered in the development of the transition zone map displayed in Figure 10b.

Figure 12: NW-SE cross-section of RFs along the profile shown in Figure 10. Black rectangles mark regions of limited to no RF-signal amplitudes at the $410 \mathrm{~km}$ or $660 \mathrm{~km}$ discontinuities (dotted lines), suggesting that at these locations, these discontinuities are poorly developed. 


\section{Figure 1}

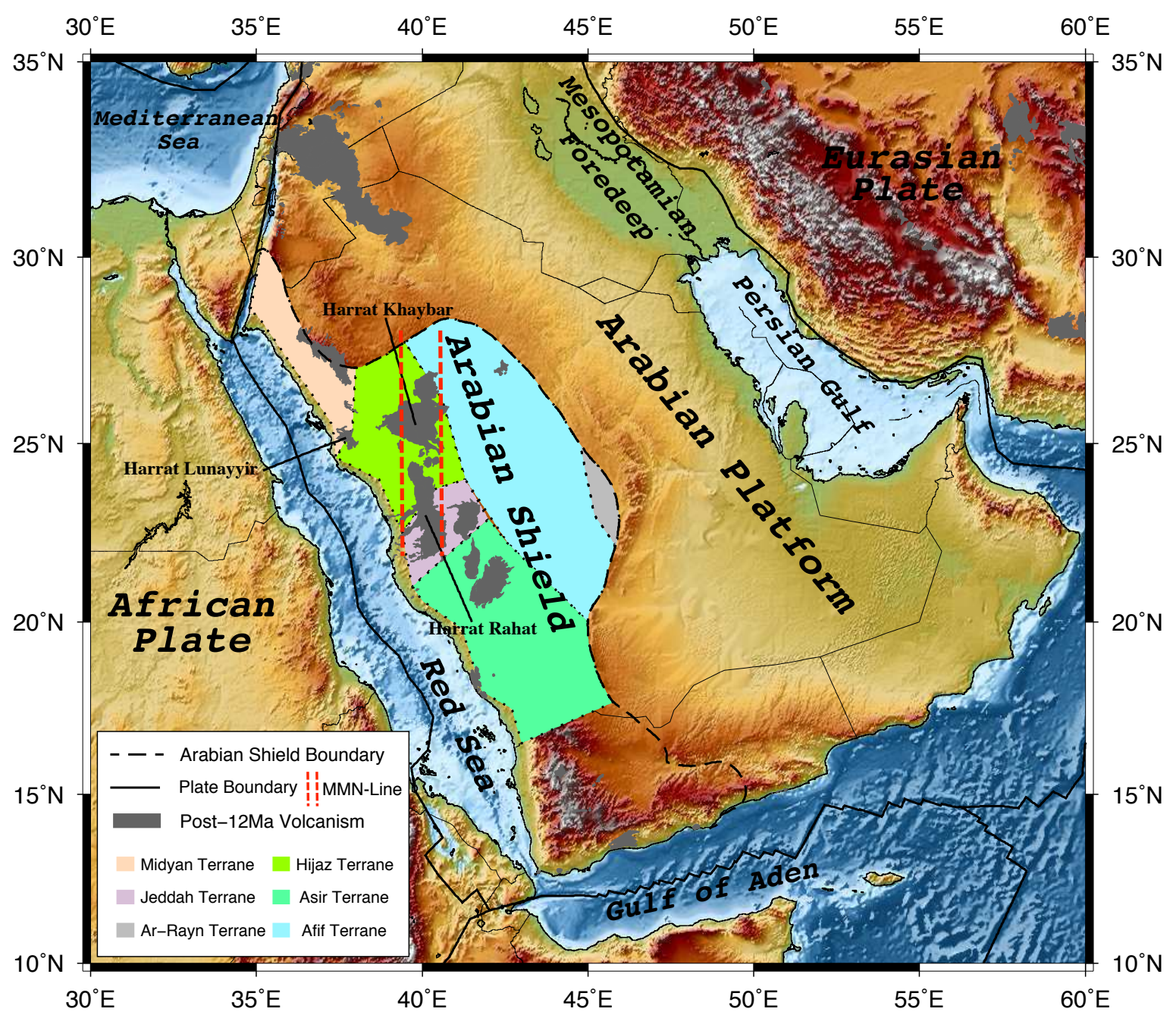




\section{Figure 2}

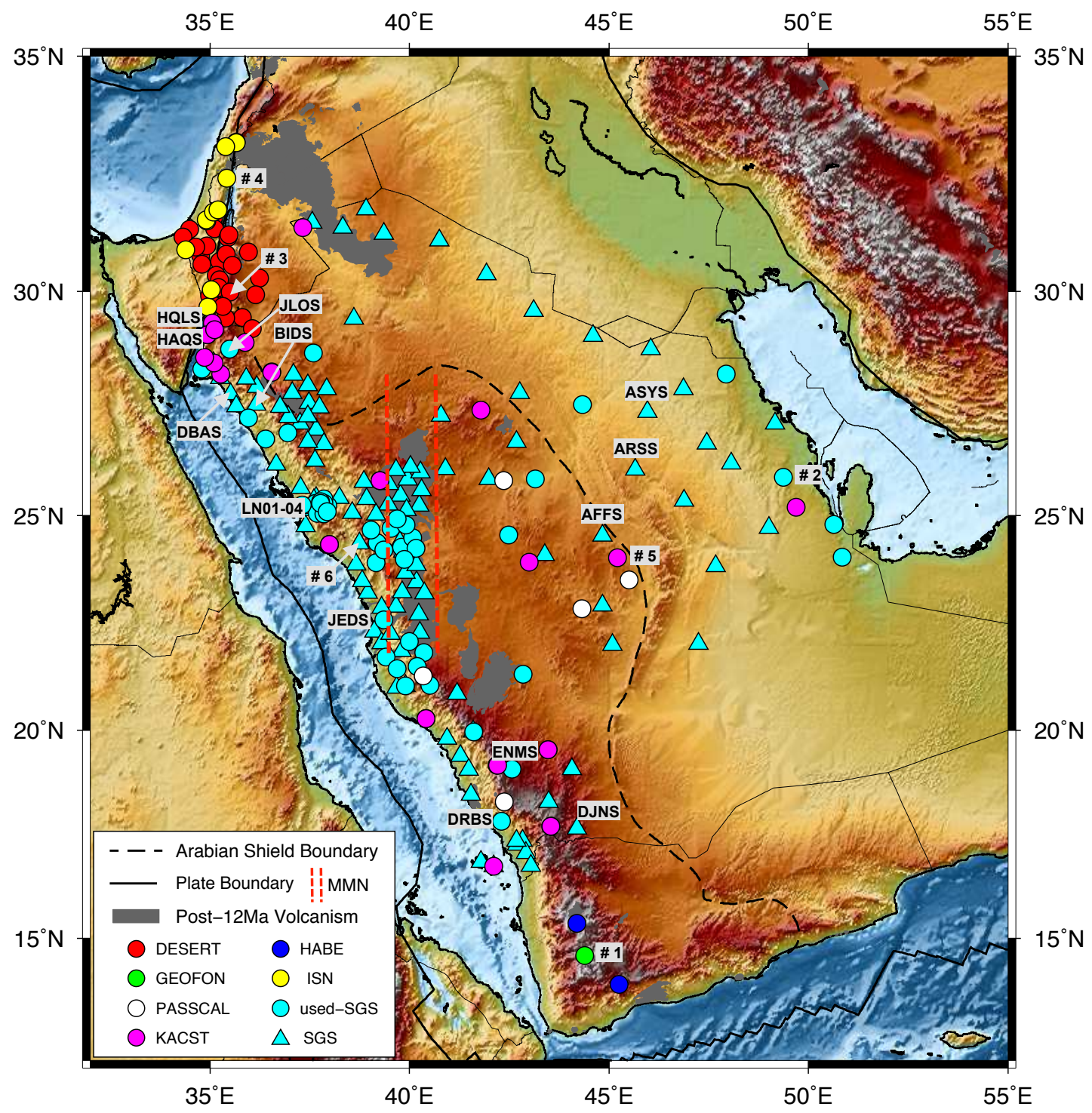


Figure 3
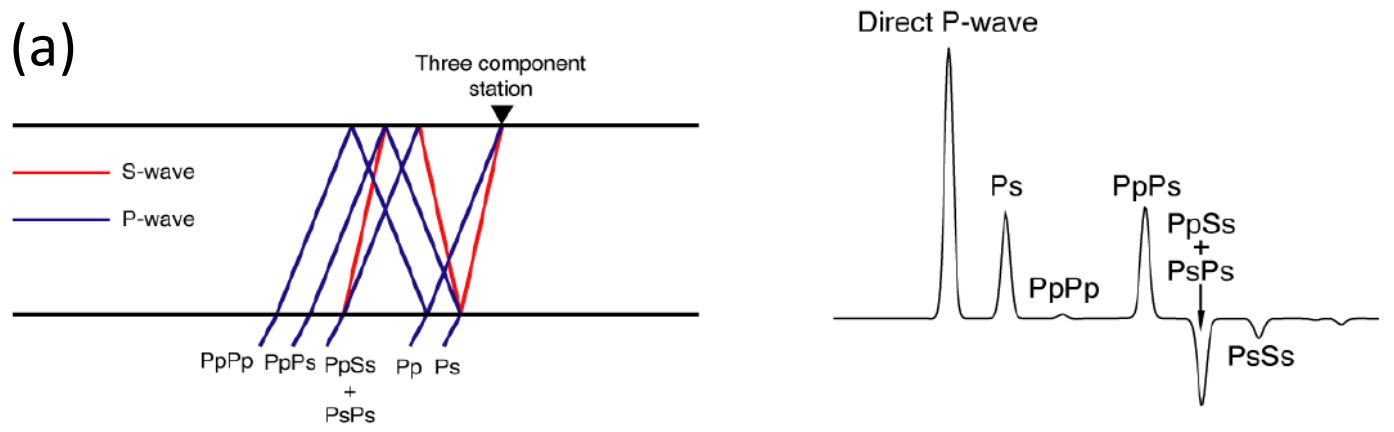

(b)
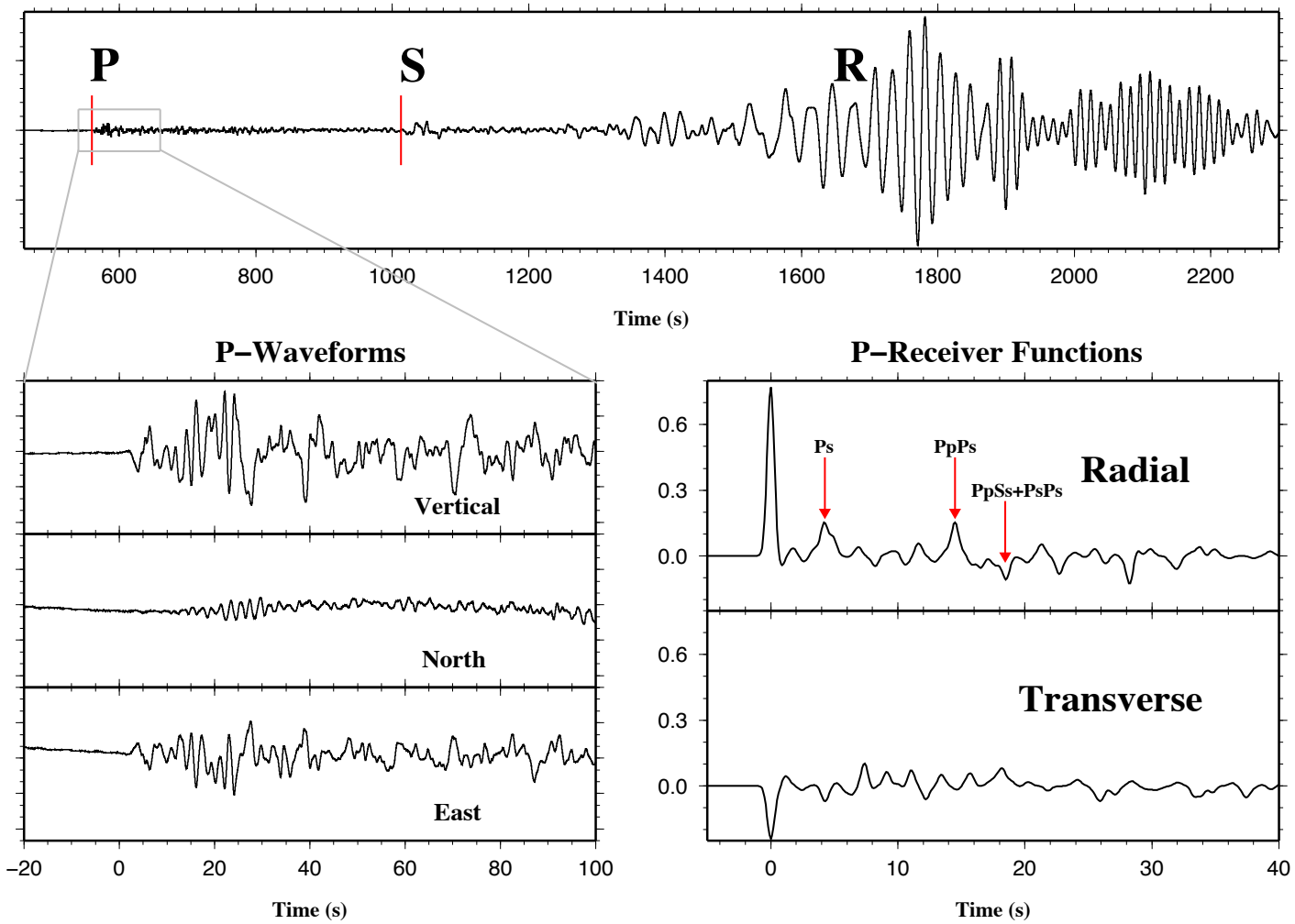

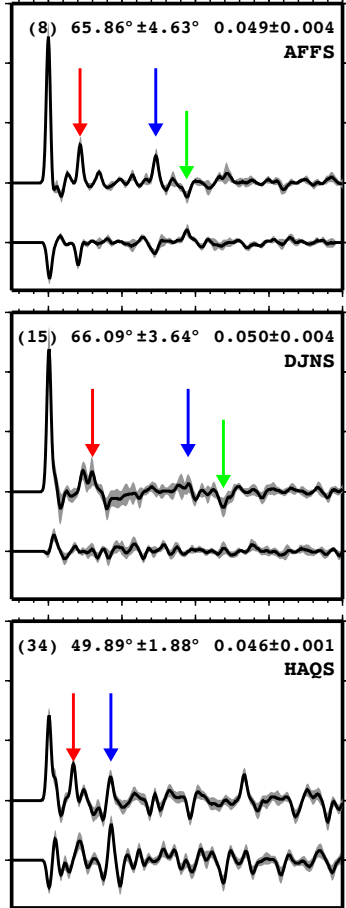

(11) $52.20^{\circ} \pm 2.69^{\circ} 0.045 \pm 0.001$

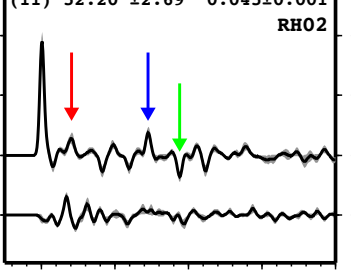

Time (s)
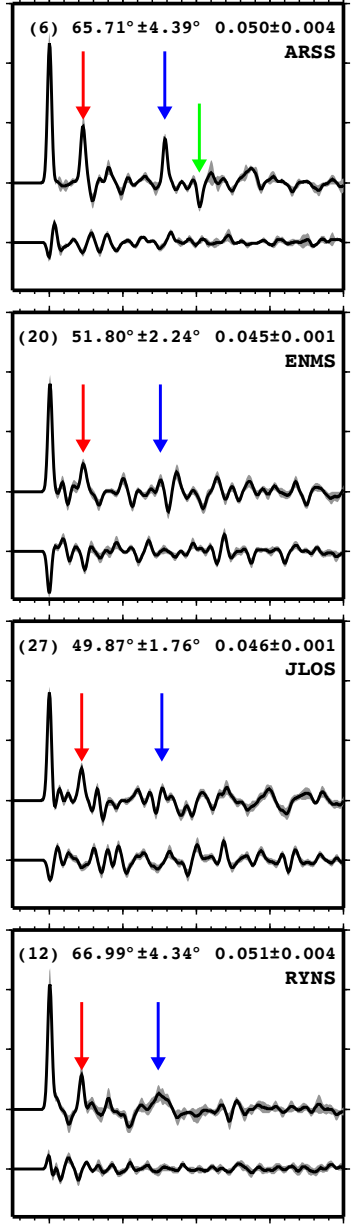

Time (s)
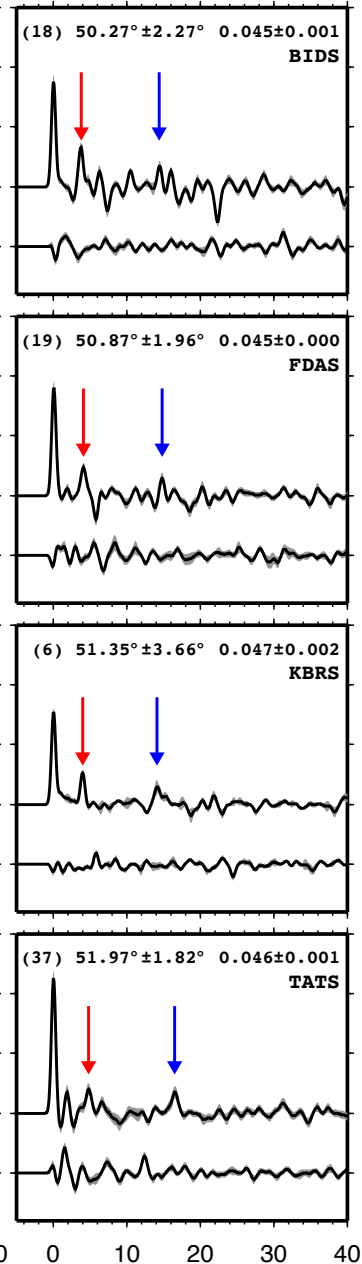

Time (s)
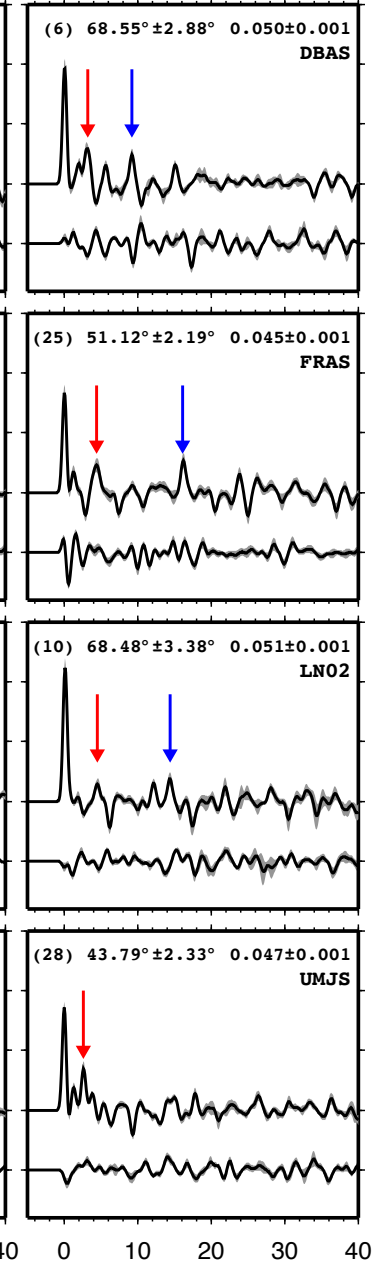

Time (s) 
Figure 5
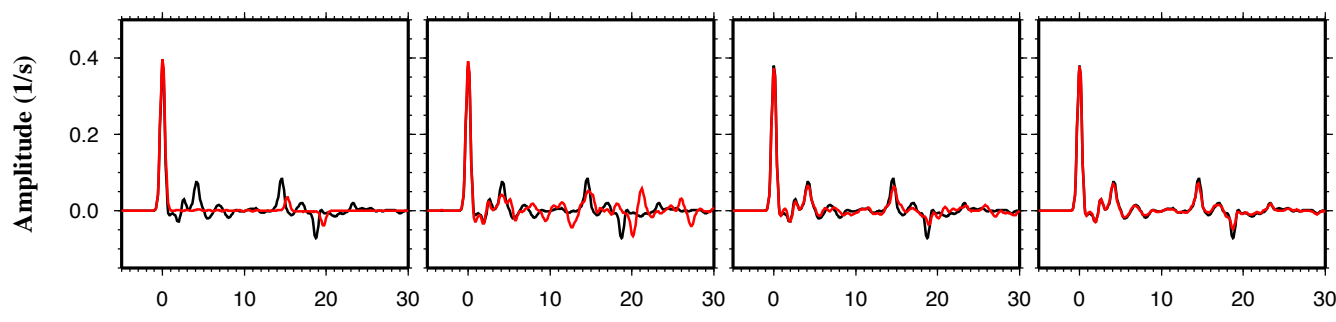

Time (s)

Time (s)

Time (s)

Time (s)
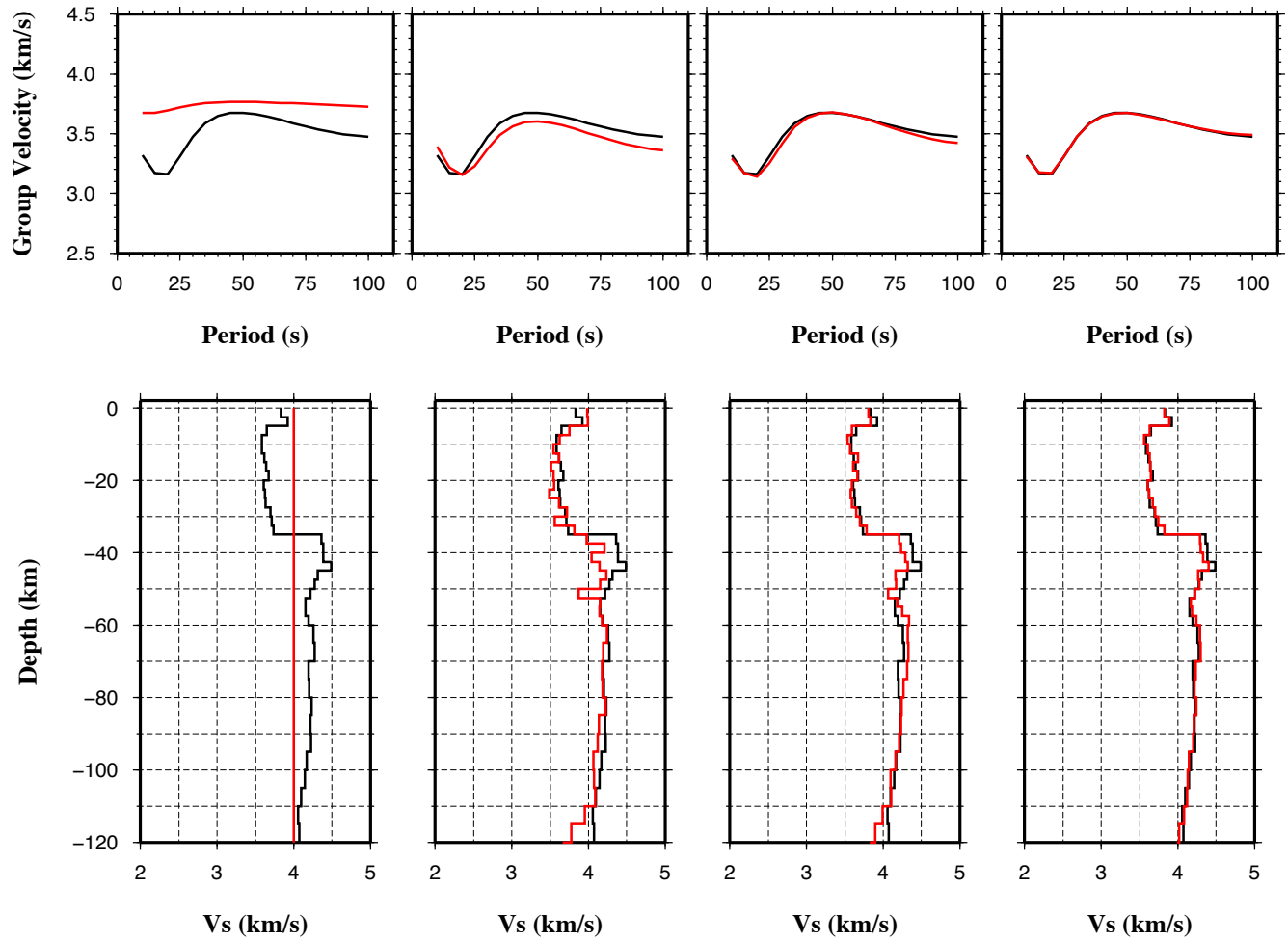


\section{Figure 6}
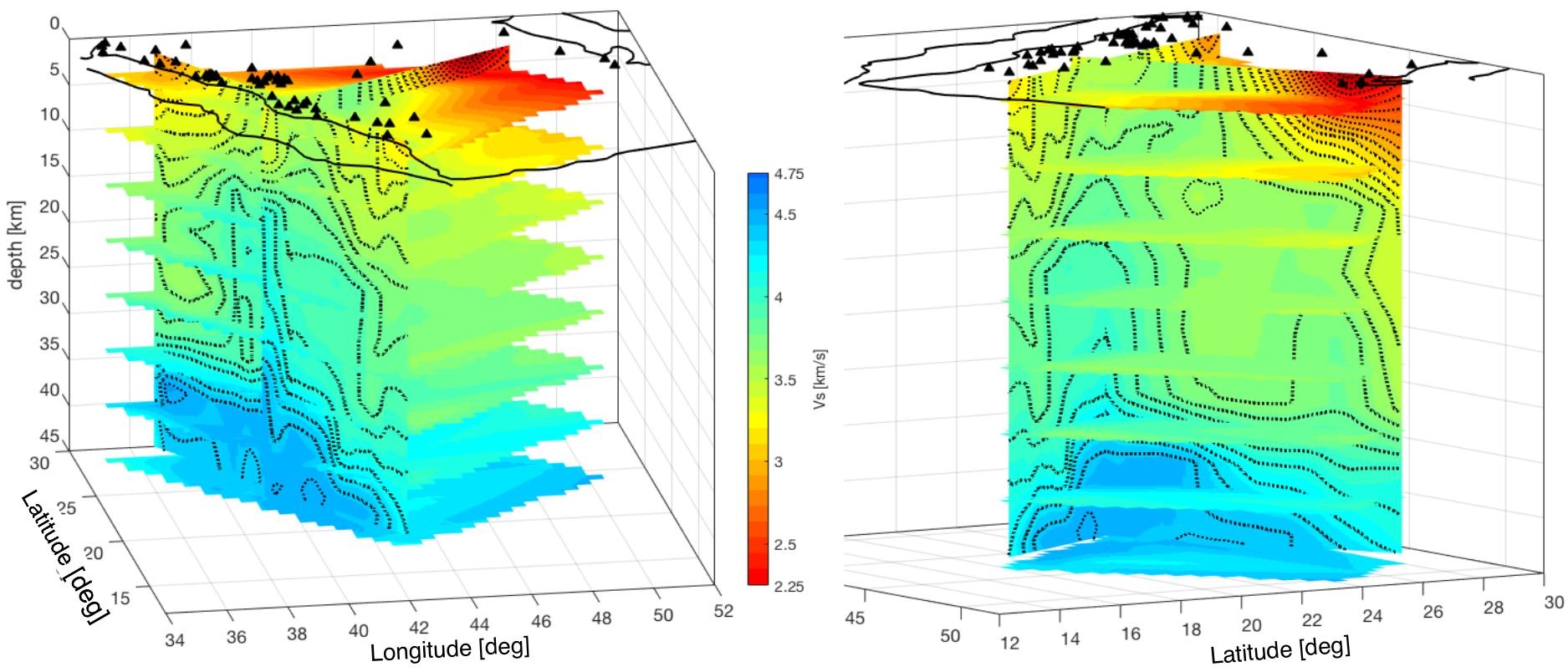
Figure 7
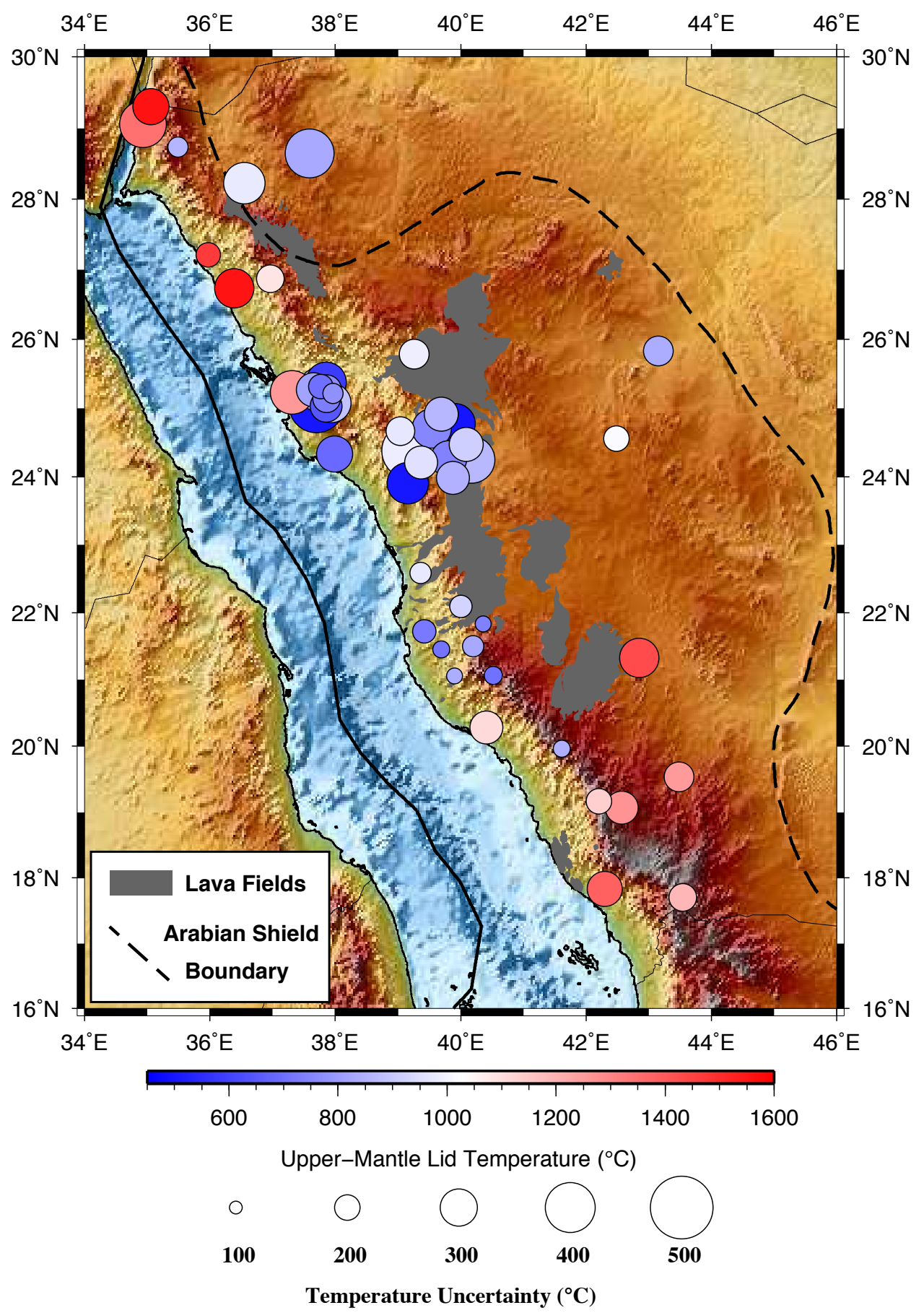
Figure 8

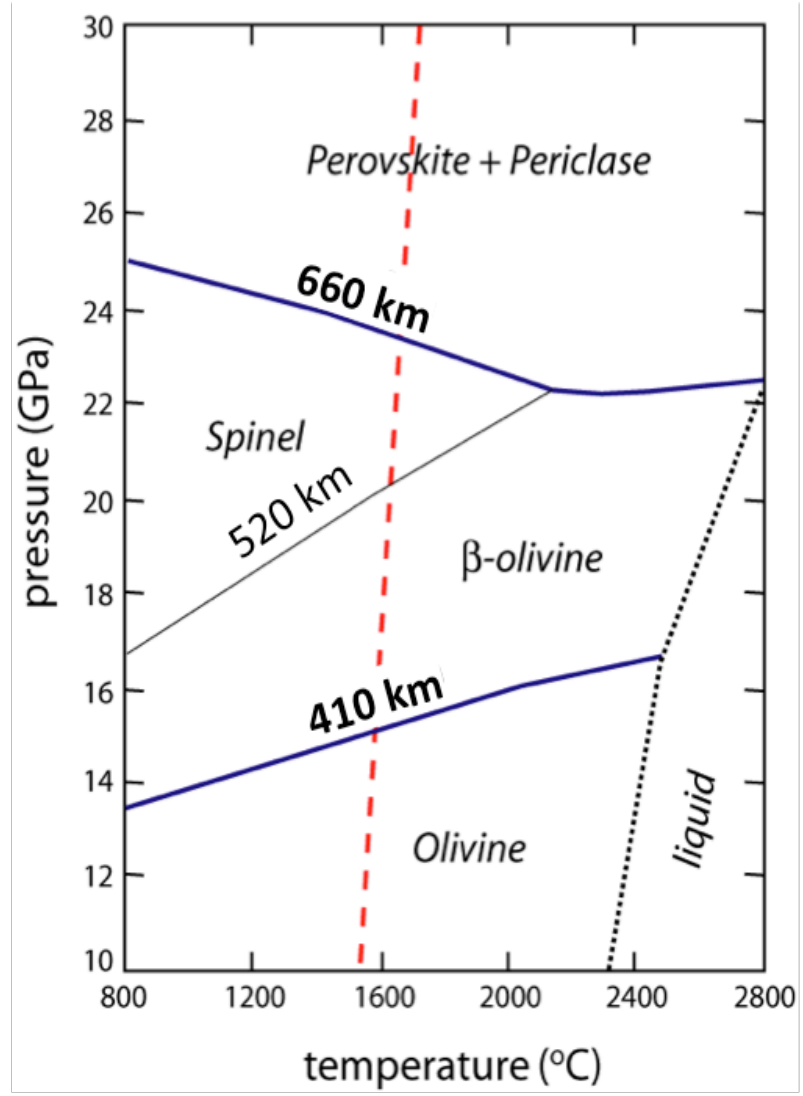


Figure 9
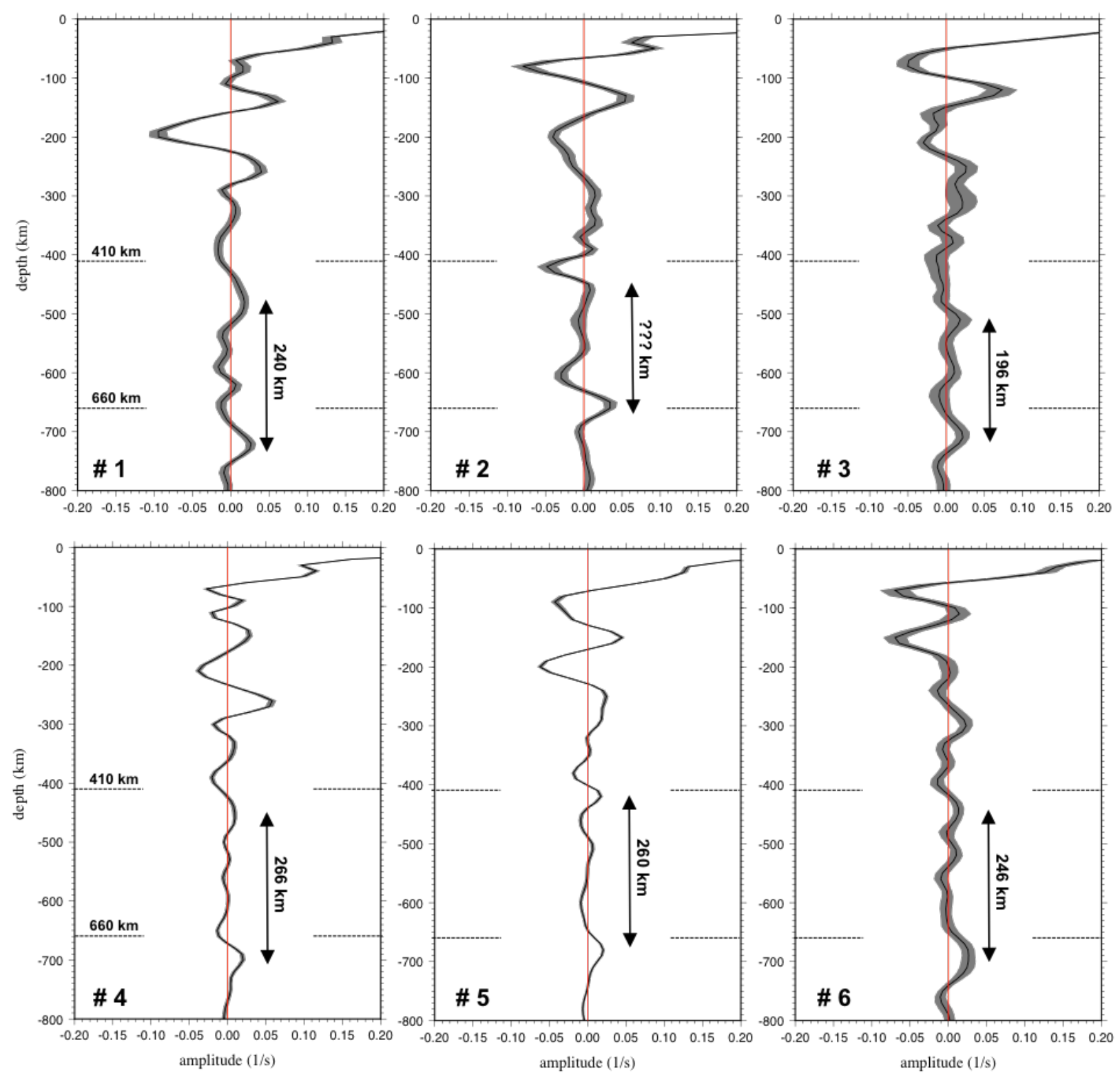
Figure 10
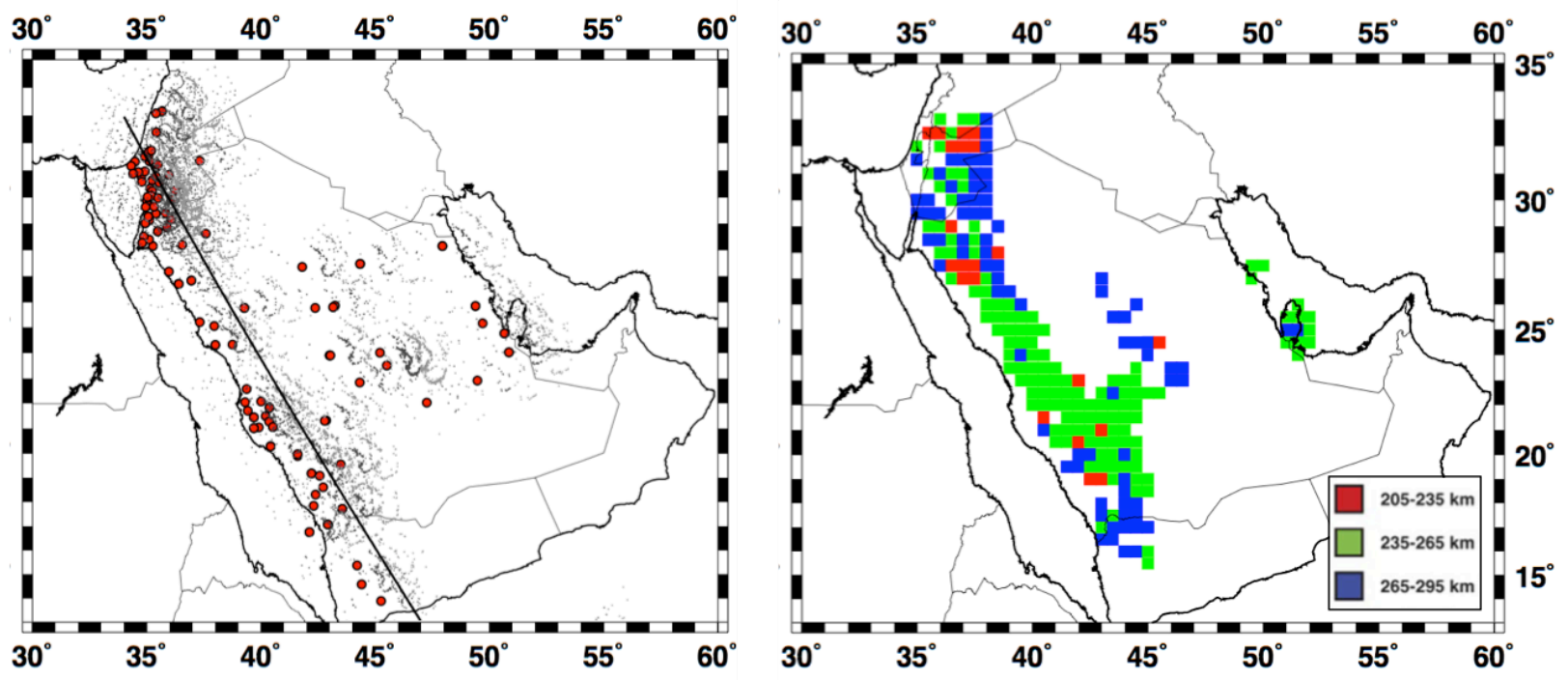
Figure 11
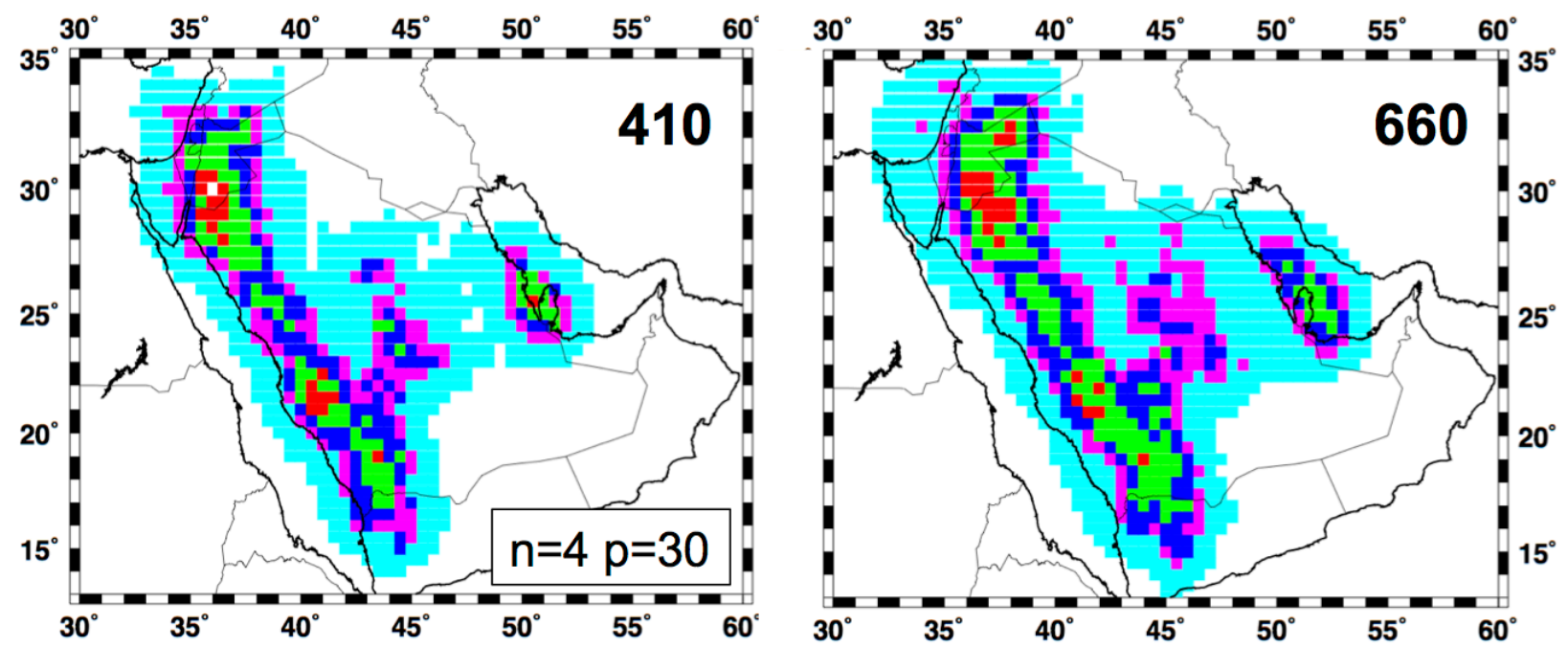

$0.25 \square 0.50$

0.75

$1.00 \square>1.00$ 
Figure 12

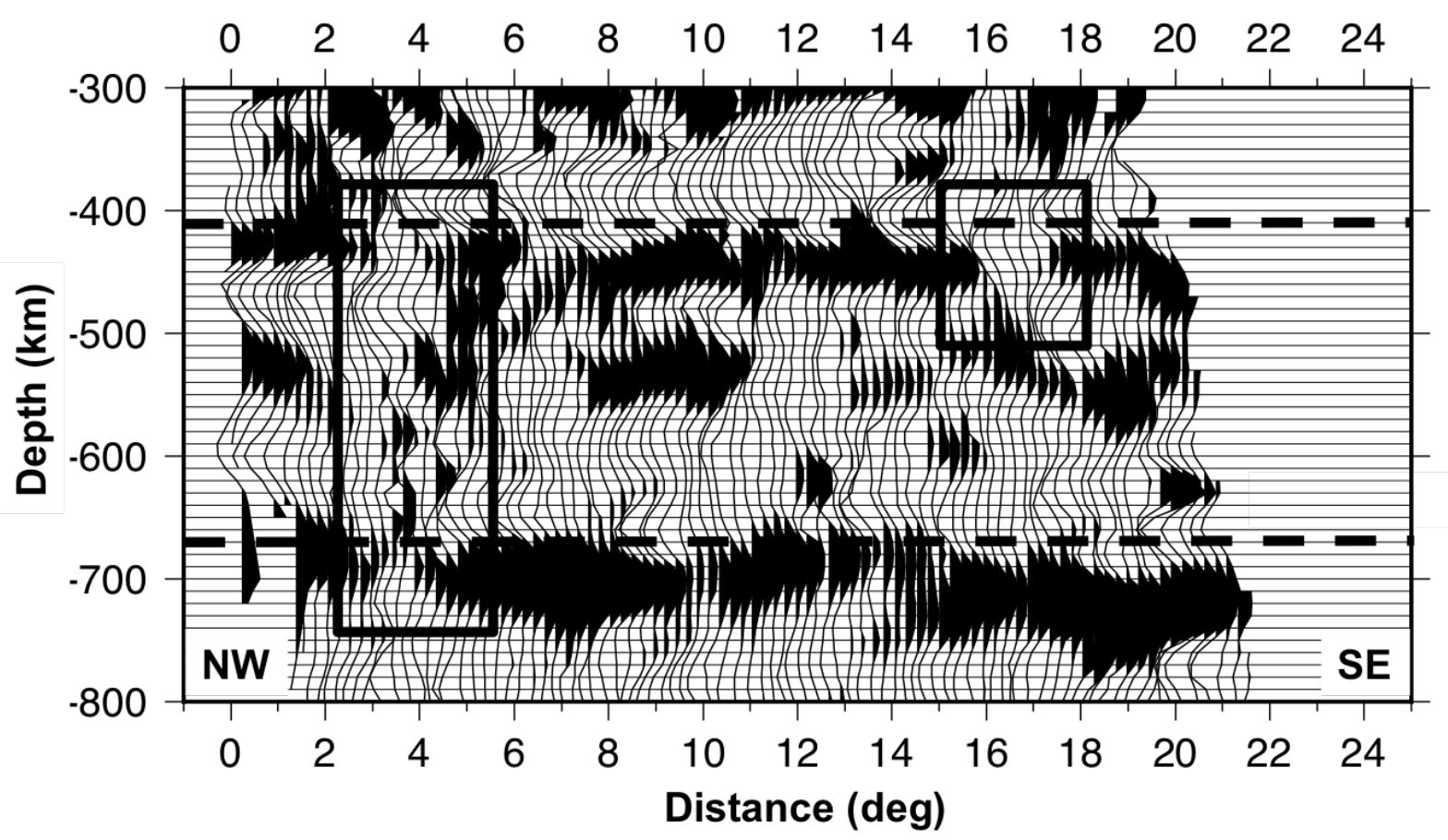

